\title{
An Analysis of Stratospheric Wave Disturbances over the Tropical Pacific
}

\author{
By Katsuaki Odo* \\ Geophysical Institute, Kyoto University, Kyoto 606, Japan \\ (Manuscript received 14 June 1976, in revised form 7 October 1976)
}

\begin{abstract}
Stratospheric wave disturbances over the tropical western Pacific during Dec. 1968-Apr. 1969 are analysed for about 10 day period. It is found that two types of disturbances which propagate in the opposite direction are dominant in this period range. One is the Kelvin wave which is prevailing below $40 \mathrm{mb}$. The other is the westward propagating disturbance observed above $40 \mathrm{mb}$, which exhibits both zonal and meridional wind fluctuations. It may be identified with the $n=1$ Rossby wave. The vertical structure of these two types of waves is compared with the calculation based upon the wave theory (Lindzen, 1971, 1972).

It has been noted by earlier studies that there exists a difference between the vertical structure of waves above and below the westerly shear zone when Kelvin waves are dominant. The present study suggests that the difference would most probably be due to the mixture of Rossby waves with Kelvin waves.
\end{abstract}

\section{Introduction}

Since the discoveries of the mixed Rossbygravity wave by Yanai and Maruyama (1966) and the Kelvin wave by Wallace and Kousky (1968), there has been extensive interest in the tropical stratospheric disturbances in the last decade. Mixed Rossby-gravity waves of the period of 4-5 days and zonal wavenumber 4 move westward, while Kelvin waves propagate eastward with 1020 day period and wavenumber 1 or 2 .

As discussed by Maruyama (1967), Lindzen and Matsuno (1968) and Holton and Lindzen (1968), such periodicity and wavenumber of these waves are consistent with the dispersion relation which is predicted by the wave theory (Rosenthal, 1965, Matsuno, 1966, and Lindzen, 1967), and also with respect to the structure of disturbances observations and theories seem to be in mutual agreement, considering that these waves are forced from below. The only exception is the result of Kousky and Wallace (1971), in which Kelvin-like waves are found in the westerly wind regime with the vertical wavelength considerably longer than that of Kelvin waves in the lower easterly regime in contrast to the theoretical prediction.

* Present affiliation: Kansai Branch, Japan Weather Association, Osaka.
In this paper we examine the tropical stratospheric disturbances over the western Pacific during the period from Dec. 1968 to Apr. 1969 in order to discuss the discrepancy between theories and observations mentioned above.

\section{Data analysis and results}

Daily 00 GMT wind and temperature data over 8 stations in the western Pacific during the period from December 1, 1968 to April 15, 1969, when the mean easterly wind is prevailing with the westerly phase of the quasi-biennial cycle descending, are used for the present study. Fig. 1 shows the vertical distribution of the mean zonal wind during this period at Truk. The list of stations used for this study is shown in Table 1.

Table 1. List of stations used for the present study.

\begin{tabular}{|c|c|c|c|}
\hline Station & Latitude & Longitude & $\begin{array}{c}\text { Station } \\
\text { identifier }\end{array}$ \\
\hline Majuro & $7^{\circ} 15^{\prime} \mathrm{N}$ & $171^{\circ} 23^{\prime} \mathrm{E}$ & M \\
\hline Koror & $720 \mathrm{~N}$ & $13429 \mathrm{E}$ & $\mathrm{K}$ \\
\hline Truk & $\begin{array}{l}728 \mathrm{~N} \\
\end{array}$ & $\begin{array}{lll}151 & 51 & \mathrm{E}\end{array}$ & $\mathrm{T}$ \\
\hline Yap & $931 \mathrm{~N}$ & $\begin{array}{lll}138 & 08 & \mathrm{E}\end{array}$ & $\mathrm{Y}$ \\
\hline Taguac & $1333 \mathrm{~N}$ & $14450 \mathrm{E}$ & G \\
\hline Johnston & $1644 \mathrm{~N}$ & $16931 \mathrm{~W}$ & $\mathbf{J}$ \\
\hline Wake & $1917 \mathrm{~N}$ & $16639 \mathrm{E}$ & W \\
\hline Midway & $2813 \mathrm{~N}$ & $17722 \mathrm{~W}$ & I \\
\hline
\end{tabular}




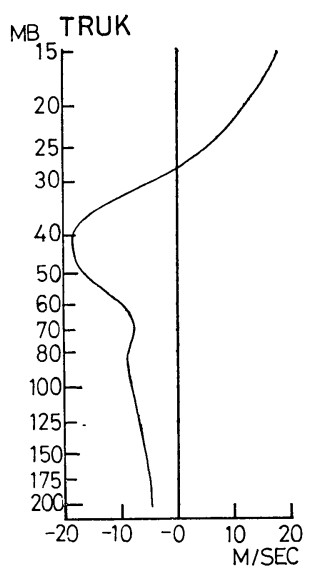

Fig. 1 Vertical distribution of the mean zonal wind at Truk during the period from Dec. 1968 to Apr. 1969.
Analyses are made at constant pressure levels of $200,175,150,125,100,80,70,60,50,40,30$, 25,20 , and $15 \mathrm{mb}$. Missing data are interpolated one dimensionally at each level by the technique of cubic splines under tension that was developed by Cline (1973), but in this case there is no practical difference from linear interpolation.

We use the power spectral and cross spectral analyses to the time series data in order to examine the structure of wave disturbances. The method of analysis is the same as that used by Yanai et al. (1968) and details of its procedure are discussed in Maruyama (1968). Prior to the spectral analysis time series data are prefiltered so as to eliminate the variations in the period range longer than 30 days.

From all the results, although somewhat differences still exist among stations as are partly illustrated in this section, it is found that the stations can be classified into two groups as follows: (A) Majuro, Koror, Truk and Yap which lie equatorward of $10^{\circ} \mathrm{N}$; (B) Wake, Johnston and Taguac which are located in the subtropical region poleward of $10^{\circ} \mathrm{N}$. Midway is the exception in this classification, probably because it is located in the mid-latitude region. In the discussions that follow, therefore, we shall show the results only at Majuro and Wake as representative stations, which are located roughly along the same meridian $170^{\circ} \mathrm{E}$

Fig. 2 shows the power spectra of the zonal and meridional wind components at Majuro and Wake. It is found that both wind components have peaks of power spectral density for periods of 7-10 days and about 20 days in the upper troposphere and/ or in the lower stratosphere, though spectral peaks are not so clearly isolated at Majuro. In all the following discussions, however, we shall concern ourselves only with 7-10 day period, because in this period range are dominantly observed two types of waves related to the problem we will discuss.

The mean structure of the disturbances for this period range is investigated by the use of cross spectral analysis technique. First of all, in order to see the longitudinal scale and the direction of propagation of disturbances, phase differences between the zonal and meridional wind components
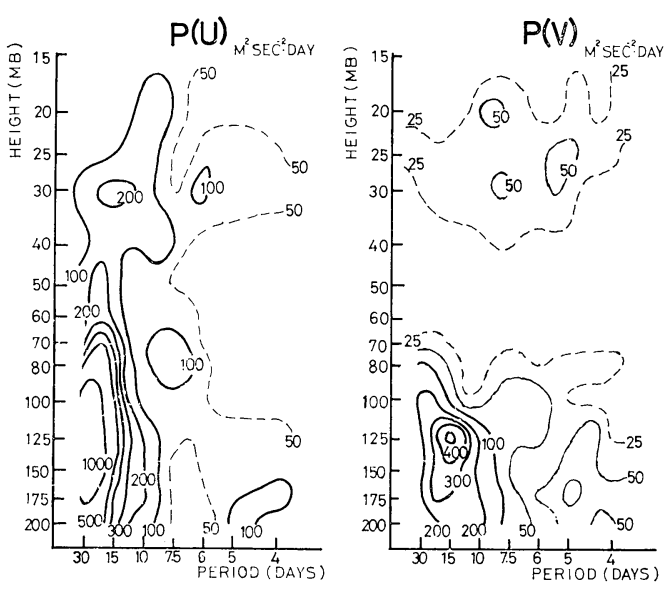

(a)
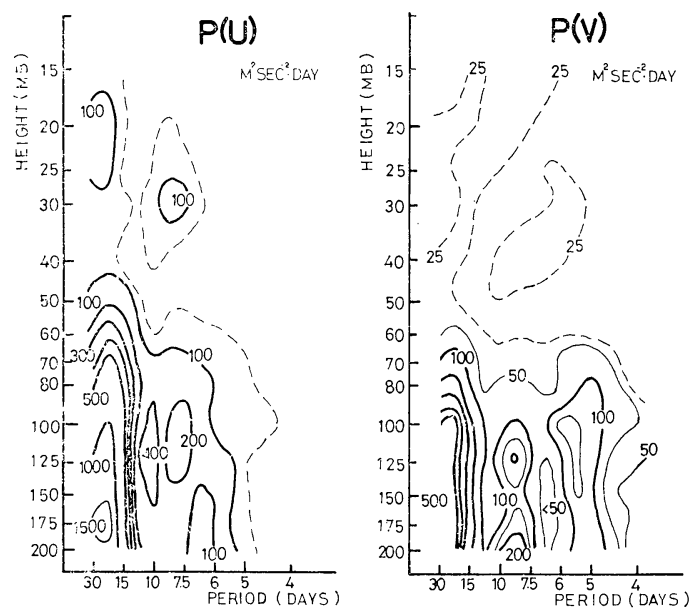

(b)

Fig. 2 Power spectra of the zonal and meridional wind components at Majuro (a) and Wake (b). 


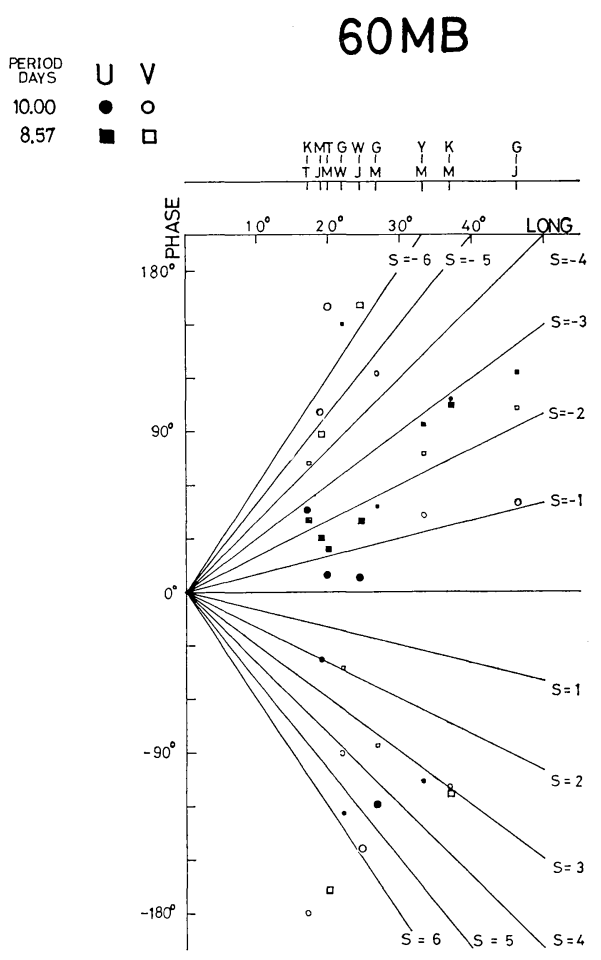

(a)
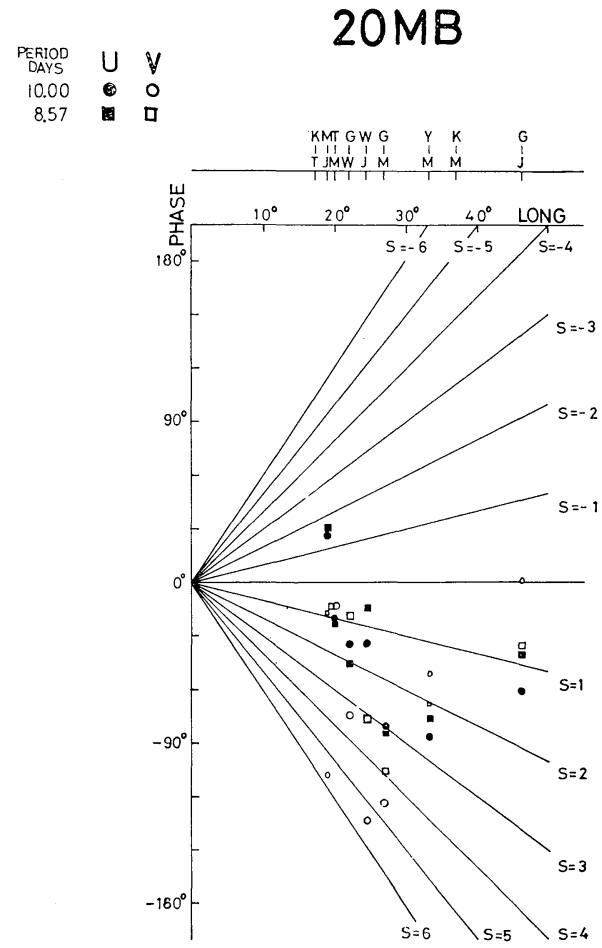

(b)

Fig. 3 Relations between the phase difference of wind variations at two stations for the period of 8.57 and 10.00 days and the longitudinal difference of the stations at $60 \mathrm{mb}$ (a) and $20 \mathrm{mb}$ (b). The latitudinal difference of the stations is ignored. The sloping line labelled with $s$ indicates the phase relation for the wave of zonal wavenumber $s$. The large circle or square denotes the value with coherence larger than 0.5 .

at various stations are examined. Fig. 3 shows the relation between the phase difference of wind fluctuations at two stations $(\Delta \theta)$ and the longitudinal difference of the stations $(\Delta \lambda)$, by ignoring the latitudinal difference of them. The sloping line labelled with $s$ indicates the phase relation corresponding to the wave of zonal wavenumber $s$. At $60 \mathrm{mb}$, though no systematic relation between $\Delta \theta$ and $\Delta \lambda$ is found for the meridional wind component, the zonal wind component reveals eastward propagation in general. Therefore, it may be considered that this disturbance is an eastward propagating wave with no meridional wind fluctuation. Contrary to this, at $20 \mathrm{mb}$ both wind components are characterized by westward propagation. The zonal wavenumber of disturbances is roughly estimated to 1-3 at both levels.

Next, the vertical structure of disturbances is examined by the use of inter-level cross spectral analysis. Fig. 4 shows the phase difference of the zonal wind component at various levels relative to the zonal wind component at $100 \mathrm{mb}$ for the period of 8.57 and 10.00 days at Majuro. It is found that the phase increases with height in the lower stratosphere. But the difference of vertical inclination between below and above $40 \mathrm{mb}$ strongly suggest there are two types of disturbances in the lower stratosphere. Considering the direction of propagation, we find that the wave axis strongly inclines eastward with height below $40 \mathrm{mb}$ while the wave above $40 \mathrm{mb}$ has a small westward inclination with height.

To see the whole structure of disturbances, we finally examine the phase relations among three quantities (temperature $\mathrm{T}$, zonal wind component $\mathrm{U}$ and meridional wind component $\mathrm{V}$ ) at each level. Theoretical studies (Lindzen, 1971, 1972) indicate that for any normal mode solution of equatorial waves the zonal wind fluctuation has a phase difference by a quarter of a cycle from 




Fig. 4 Phase differences of the zonal wind component at various levels relative to the zonal wind component at $100 \mathrm{mb}$ for the period of 8.57 and 10.00 days at Majuro. The large circle or square denotes the value with coherence larger than 0.5 .

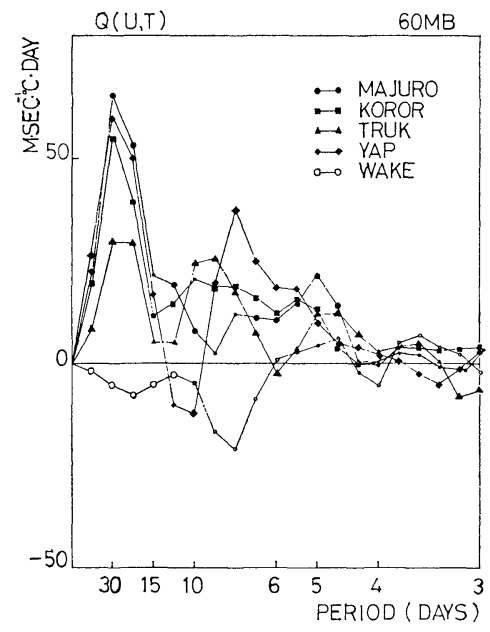

(a) the temperature and also from the meridional wind component with the exception of Kelvin mode which has no meridional wind fluctuation. Therefore, the characteristics of disturbances corresponding to the normal mode should be most clearly illustrated for the spectral peaks of quadrature spectral estimates $Q(\mathrm{U}, \mathrm{T})$ and $Q(\mathrm{U}, \mathrm{V})$ and co-spectral estimate $C(\mathrm{~V}, \mathrm{~T})$. (Regarding the quadrature and co-spectrum, see Maruyama (1968) for example.) In this paper, to avoid the complicatedness, we shall illustrate the frequency distribution of $Q(\mathrm{U}, \mathrm{T})$ and $Q(\mathrm{U}, \mathrm{V})$ only at 60 and $20 \mathrm{mb}$, not the frequency-height section such as Fig. 2. Unfortunately as for $C(\mathrm{~V}, \mathrm{~T})$, no systematic relation is obtained possibly due to random noise in temperature data and to the smallness of power spectral density of the temperature and meridional wind component in comparison with the zonal wind component, so the result is not shown.

Fig. 5(a) illustrates the quadrature spectra $Q(\mathrm{U}, \mathrm{T})$ at $60 \mathrm{mb}$. At Majuro no spectral peak appears in the frequency range under consideration at this level, but at other stations classified into station group (A), i.e. Koror, Truk and Yap, positive peak appears. The results at these stations are also illustrated in Fig. 5(a). The phase relation between the zonal wind component and the temperature obtained by the cross spectral analysis is somewhat scattered, probably due to random noise in temperature data as previously



(b)

Fig. 5 Quadrature spectra between the zonal wind component and the temperature at $60 \mathrm{mb}$ (a) and $20 \mathrm{mb}$ (b). The large symbol denotes the value with coherence larger than 0.5 . 
mentioned. It is found at Majuro that the temperature fluctuation leads to the zonal wind component by more than a quarter of a cycle. However, at Koror, Truk and Yap, as is easily expected from Fig. 5(a), it is revealed below $40 \mathrm{mb}$ in the lower stratosphere that the temperature fluctuation leads to the zonal wind component by about a quarter of a cycle, the phase relation just expected for the Kelvin wave from the theory. Inversely, negative peak of $Q(\mathrm{U}, \mathrm{T})$ appears at Wake, suggesting that pure Kelvin waves do not propagate in the latitudinal belt near Wake. Contrary to the situation at $60 \mathrm{mb}$, as is suggested from the negative spectral peak of $Q(\mathrm{U}, \mathrm{T})$ shown in Fig. 5(b), the temperature fluctuation lags behind the zonal wind component at $20 \mathrm{mb}$ at many stations, but its phase difference is rather dispersed and ranges from $30^{\circ}$ to $150^{\circ}$. Since the negative peak is not so conspicuous at Wake, we also illustrate the results at Johnston and Taguac which are classified into the same station group as Wake.

As regards the phase relation between the zonal and meridional wind components, it is found at most stations that the zonal wind component tends to lag behind and lead to the meridional wind component below and above $50-60 \mathrm{mb}$ in the lower stratosphere, respectively. Fig. 6(a) and 6(b) represent the quadrature spectra $Q(\mathrm{U}, \mathrm{V})$ at 60 and $20 \mathrm{mb}$, respectively. At $60 \mathrm{mb}$ there appears no dominant spectral peak, while at $20 \mathrm{mb}$ negative peaks are remarkable in the 7-10 day period range, indicating that the meridional wind component lags behind the zonal wind component. Supposing that only Kelvin waves exist at $60 \mathrm{mb}$, it is to be expected that $Q(\mathrm{U}, \mathrm{V}) \sim 0$ at this level.

In view of the whole structure of disturbances mentioned above, we are inclined to view 7-10 day period disturbances as a combination of two types of waves, one corresponding to the Kelvin wave and the other a certain type of westward propagating wave. It has been known that the Yanai-Maruyama wave is the most prominent westward moving wave observed in the lower stratosphere and corresponds to the mixed Rossbygravity wave in the theory. However, the structure of westward propagating wave in the present analysis is not consistent with that of mixed Rossby-gravity wave, because for the latter wave the zonal wind component must lag behind the temperature and the meridional wind component at the station in the northern hemisphere, a somewhat opposite sense to the present results. Therefore, we may speculate that the present disturbance is the $n \geq 1$ Rossby wave where $n$ is the order of Hermite polynomials. For the $n=1$ Rossby wave the zonal wind component must lead to the temperature and the meridional wind component by a quarter of a cycle at the station equatorward from the center of the vortex in the northern hemisphere.

To confirm the relation between these two types of waves in this period range, the day-to-day variation of wind vector of 7-10 day period

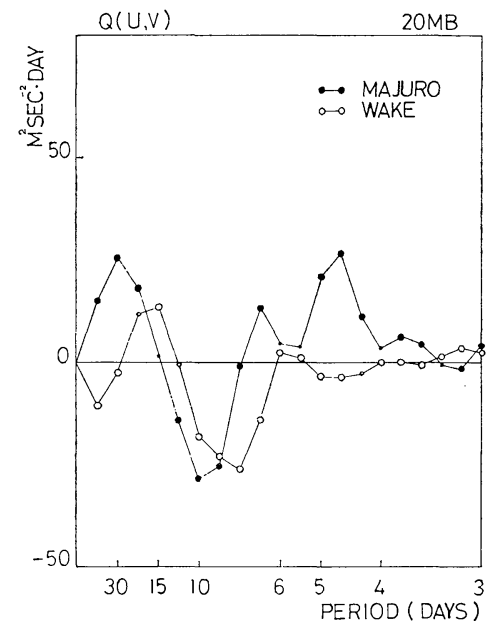

(b)

(a)

Fig. 6 Quadrature spectra between the zonal and meridional wind components at $60 \mathrm{mb}$ (a) and $20 \mathrm{mb}$ (b). The large symbol denotes the value with coherence larger than 0.5 . 
through a band-pass filter is shown in Fig. 7 during the period from Jan. 10 to 18,1969 . At Majuro the zonal oscillation is evident at $60 \mathrm{mb}$, implying a predominance of Kelvin waves. On the other hand at $20 \mathrm{mb}$ the wind vector turns counterclockwise, probably implying some contributions due to Rossby waves. This situation is more evident at Wake. From Lindzen's analytical solutions (1972) using the same parameters as will be shown in the later paragraph, the center of the vortex of the $n=1$ Rossby wave is calculated to be about $27^{\circ}$ latitude at $20 \mathrm{mb}$. These

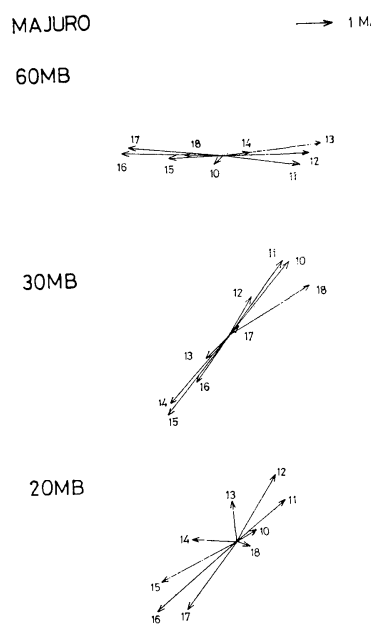

(a)

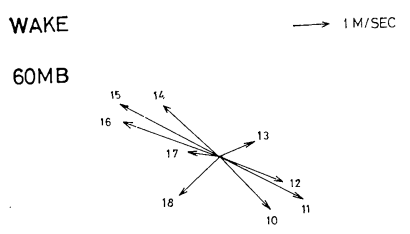

$30 \mathrm{MB}$

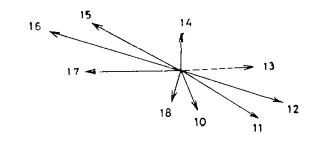

$20 \mathrm{MB}$

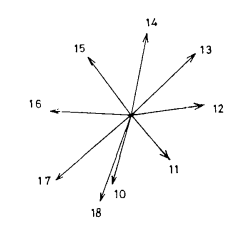

(b)

Fig. 7 Examples of the day-today variation of wind vector of 7-10 day period through a band-pass filter. The numeral denotes the date of Jan. 1969. results appear to support our earlier conjecture that Kelvin waves are dominant below $40 \mathrm{mb}$ and $n=1$ Rossby waves are prevailing above.

The possibility of $n=1$ equatorial Rossby waves in the atmosphere was first noted by Yanai and Murakami (1970) and later by Nitta (1972) by the use of spectral analysis method. Yanai and Murakami found westward propagating disturbances of the period of about 7 days and wavelength of about $9000 \mathrm{~km}$ with maximum amplitude in the upper troposphere. They identified these waves with $n=1$ Rossby mode in the theory (Matsuno, 1966) and further mentioned that the horizontal structure of these waves was similar to that of horizontal eddies analyzed in timelatitude section at $200 \mathrm{mb}$ by Yanai (1963) and at many levels by Yanai and Hayashi (1969). Gruber (1975) confirmed their results by the wavenumberfrequency spectral analysis of 1970-1971 wind data at $200 \mathrm{mb}$. However, there seems to be no definitive observational evidence of equatorial $n=1$ Rossby waves as dominant disturbances in the stratosphere. Comparison of the present result with the earlier studies mentioned above reveals that the preferred period of $n=1$ Rossby waves is in nearly agreement, although the results concerning the structure of long wave disturbances calculated on the basis of localized station data must be regarded as tentative. This resemblance in periodicity might suggest that stratospheric disturbances observed in the present study are upward extension of tropospheric ones analyzed by the earlier investigators, but detailed comparison and mutual relationship, if possible, are in need of further investigation.

Finally, we calculate the vertical structure of waves based on the equatorial wave theory taking account of the vertical wind shear (Lindzen, 1971, 1972) and compare it with the vertical structure of observed waves. In Fig. 8 is shown the vertical distributions of the amplitude at the point $1000 \mathrm{~km}$ away from the equator and of the phase of the zonal wind component for the Kelvin and $n=1$ Rossby waves. The amplitude is normalized to unity at $17 \mathrm{~km}$. In this procedure, it is assumed that the Kelvin and $n=1$ Rossby waves are both excited in the same frequency range in the upper troposphere. The numerical values of parameters adopted for these calculations are as follows; 1) the zonal wavenumber $|s|=1$ or 2,2 ) the frequency $\omega=2 \pi / 10$ days $^{-1}$ corresponding to the maximum power of the zonal wind component, 3) Newtonian cooling rate $\alpha=1 / 12.5$ days $^{-1}$, and 4) the mean zonal wind $\bar{u}=$ the mean flow at Truk 


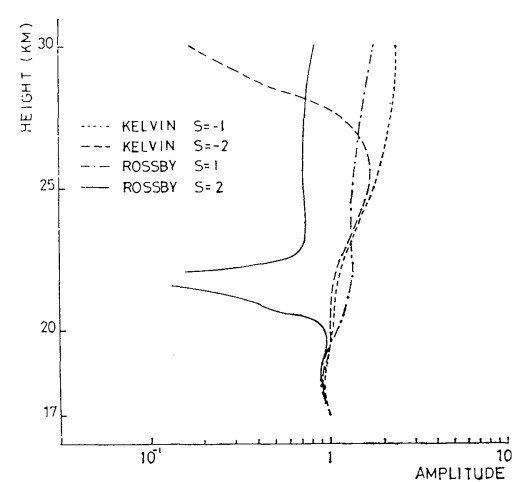

(a)

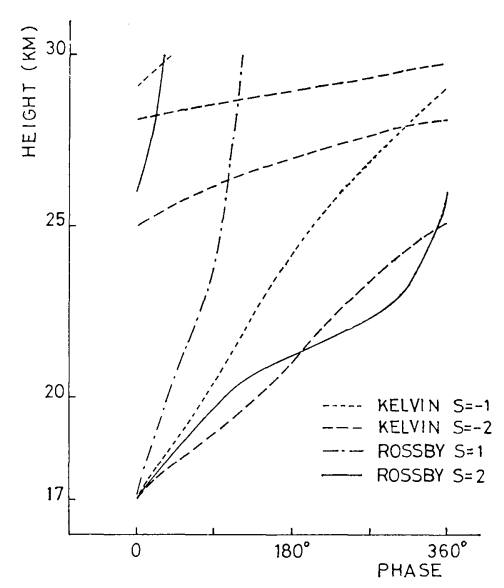

(b)

Fig. 8 Vertical distributions of the amplitude (a) at the point $1000 \mathrm{~km}$ away from the equator and of the phase (b) of the zonal wind component for the Kelvin and $n=1$ Rossby waves, calculated on the basis of Lindzen's theoretical solutions. The amplitude is normalized to unity at $17 \mathrm{~km}$.

shown in Fig. 1. Given $\bar{u}$ and $\omega$, only $|s|=1$ or 2 is theoretically permitted for which a critical level does not exist. We see that $s=-2$ provides a better fit than $s=-1$ does both for the observed vertical distribution of the amplitude and for that of the phase for the Kelvin wave. Considering the smoothing effect in wind aloft observations as is discussed by Lindzen and Tsay (1975), the maximum of the amplitude should be expected to appear at the lower levels in observations. On the other hand for the $n=1$ Rossby wave, $s=1$ seems to be in nearly agreement with the observed vertical phase relation, while $s=2$ reveals the phase lag behind the observation or calculated $s=1$ wave about a quarter of a cycle above $23 \mathrm{~km}$. However, there seems to be no definitive difference between $s=1$ and $s=2$ waves in the vertical inclination above the westerly shear level or in the vertical distribution of the amplitude.

\section{Vertical structure of waves}

Kousky and Wallace (1971) noted the Kelvinlike waves of 10-20 day period in the westerly wind regime above the westerly shear zone. This result has appeared to be the only exception that observations conflict with wave theories. Wallace (1973) remarked on these disturbances as follows: "The long vertical wavelength of these disturbances and the existence of a small meridional velocity component could be explained if one identified them with the $n=1$ Rossby mode (Matsuno, 1966), but this interpretation would be inconsistent with the observations which indicate that the waves propagate eastward and are narrowly confined about the equator."

Lindzen (1971) interprets that both the upper and the lower waves are primarily a single mode, i.e., Kelvin mode, and that the levels of observations above $40 \mathrm{mb}$ are insufficiently close to resolve waves with such short vertical wavelengths. However, observations reveal the irregular phase variation only about $40 \mathrm{mb}$ and it is regular in the upper or lower wind regime, respectively. Moreover, while the smoothing effect in wind aloft observations and the infrared cooling effect should reduce the amplitude of Kelvin waves, observations reveal the maximum power above the shear zone. Thus this problem would not appear to be well explained by considering Kelvin waves only. The present author is inclined to think that the difference in the vertical phase relation is due to the mixture of $n=1$ Rossby waves in the same frequency band as Kelvin waves are observed and that Rossby waves contribute larger than Kelvin waves to the estimation of the vertical phase difference.

In estimating the horizontal phase difference, eastward or westward propagation will be resulted according as Kelvin or Rossby waves are dominant, respectively. However in the estimation of the vertical phase difference the problem will not be so simple. Waves interact with the mean flow and the vertical structure of waves is changed by the temporarily changing mean flow. Therefore 
the vertical wavenumber $f$ is in practice a function of Doppler shifted frequency $\widehat{\omega}$. The changing rate $d f / d \hat{\omega}$ is the inverse of the vertical group velocity, so that this effect is more pronounced for a wave with small $\widehat{\omega}$. Consequently, when evaluating the covariance between two levels with vertical distance $\delta$, the wave phase difference $f \delta$ largely changes with time through $\widehat{\omega}$, resulting in a reduction of the contribution of Kelvin waves in the westerly shear zone and to a lesser extent of Rossby waves in the easterly shear zone due to the cancellation in the averaging procedure. This will possibly account for the phase relation observed above and below the westerly shear. From the theoretical calculation of the vertical structure for the mixed Rossby-gravity mode based upon the three-month mean flow and the individual monthly mean zonal wind, Lindzen and Tsay (1975) concluded that there is probably no meaning to a three-month mean phase above the easterly shear level. This conclusion will also be true for the Kelvin mode in the westerly shear.

Kousky and Wallace (1971) noted that eastward propagating waves in the westerly wind regime have somewhat larger zonal wavelength than the Kelvin waves in the easterly regime, and Wallace and Kousky (1968) reported that above $40 \mathrm{mb}$ disturbances move westward between Balboa and Trinidad. Although they were interested in the disturbances of rather longer period than ours, their results could also be explained by the mixture of Rossby waves with Kelvin waves. Furthermore, it is to be expected that Kelvin waves are relatively active in these periods, when westerly wind was rather weak. The present period is marked by a strong westerly shear. In connection with the present problem, it must be remarked that in the maximum easterly wind regime $\hat{\omega}$ will be reduced for $n=1$ Rossby waves to almost the same extent as that for Kelvin waves in the westerly, but that Rossby waves seem to be less attenuated than Kelvin waves. This can be explained physically by considering the vertical group velocity for the two types of waves. Assuming Boussinesq fluid for simplicity, we find so that it is approximated as follows

$$
C_{G} \text { Rossby } \sim(2 n+1) \frac{a \Omega}{\sqrt{g S}} \cdot \frac{\hat{\omega}^{2}}{s \Omega} \quad \text { as } \hat{\omega} \rightarrow 0
$$

where $S$; the stability parameter, $g$; the accerelation of gravity, $\Omega$; the angular frequency of the earth, and $a$; the radius of the earth.

$$
C_{G} \text { Rossby } \sim(2 n+1) C_{G} \text { Kelvin } \quad \text { as } \widehat{\omega} \rightarrow 0
$$

This implies that Rossby waves have at least larger vertical group velocity than Kelvin waves near critical level.

\section{Summary and remarks}

Tropical stratospheric disturbances over the western Pacific during the period from Dec. 1968 to Apr. 1969 are analysed and disturbances of 7-10 day period are found to be predominant. From the structure and behaviour of these disturbances it is found that Kelvin waves are dominant below $40 \mathrm{mb}$ while Rossby type waves are prevailing above. These results seem to be consistent with the theoretical calculation based on Lindzen's analytical solutions. It has been noted that there exists a difference between the vertical structure of the waves above and below the westerly shear zone when Kelvin waves are dominantly observed. The present results suggest that the difference would probably be due to the mixture of Rossby waves with Kelvin waves.

However, this study is insufficient in that the symmetry about the equator, which is essential for identifying the equatorial wave disturbances, cannot be investigated because of sparsity of stations.

So far it has been implicitly assumed that Lindzen's theoretical solutions are applicable for the period of the present study in theoretical interpretation of the observed waves. A good correspondence of the solutions with observations probably imply that this theory expresses fairly well actual equatorial waves in the atmosphere. However one of the assumptions for deriving the solutions, that the characteristic scale for the variation of $\bar{u}$ is much larger than the characteristic

$$
\begin{aligned}
C_{G} \text { Rossby }= & \frac{2 n+1}{2} \cdot \frac{a \Omega}{\sqrt{g S}} \cdot \frac{\widehat{\omega}^{2}}{s \Omega} \\
& \cdot \frac{\left[1-\left(\frac{\hat{\omega}}{\Omega}\right)^{2}\left(\frac{s}{2 n+1}\right)^{2}\left(\frac{2 \Omega}{s \hat{\omega}}-1\right)\right]^{1 / 2}\left\{1+\left[1-\left(\frac{\hat{\omega}}{\Omega}\right)^{2}\left(\frac{s}{2 n+1}\right)^{2}\left(\frac{2 \Omega}{s \hat{\omega}}-1\right)\right]^{1 / 2}\right\}^{2}}{1+\left[1-\left(\frac{\hat{\omega}}{\Omega}\right)^{2}\left(\frac{s}{2 n+1}\right)^{2}\left(\frac{2 \Omega}{s \hat{\omega}}-1\right)\right]^{1 / 2}+\left(\frac{s}{2 n+1}\right)^{2}\left[-\frac{s}{2}\left(\frac{\hat{\omega}}{\Omega}\right)^{3}+\frac{5}{2}\left(\frac{\hat{\omega}}{\Omega}\right)^{2}-\frac{3}{s}\left(\frac{\hat{\omega}}{\Omega}\right)\right]}
\end{aligned}
$$


vertical scale of waves, might be a severe requirement for $n=1$ Rossby waves, whose vertical wavelength is relatively long even in the shear zone. Furthermore the large meridional scale of Rossby waves would suggest the horizontal shear of the mean flow cannot be ignored. More complete theoretical approach will be required as well as more detailed observational studies in future for the full understanding of the dynamics of equatorial waves.

\section{Acknowledgements}

The author would like to express his hearty thanks to Messrs. K. Kawahira, H. Ito, and F. Watanabe for their valuable discussions and kind advice throughout this work. Their support and encouragement was essential for the accomplishment of the present study. The author is deeply indebted to Prof. I. Hirota for his critical reading of the manuscript and various comments. Thanks are extended to Miss S. Yanabu for typing the manuscript.

\section{References}

Cline, A. K., 1973: Curve fitting using splines under tension. Atmospheric Technology, 3. 60-65.

Gruber, A., 1975: The wavenumber-frequency spectra of the $200 \mathrm{mb}$ wind field in the tropics. J. Atmos. Sci., 32, 1615-1625.

Holton, J. R., and R. S. Lindzen, 1968: A note on "Kelvin" waves in the atmosphere. Mon. Wea. Rev., 96, 385-386.

Kousky, V. E., and J. M. Wallace, 1971: On the interaction between Kelvin waves and the mean zonal flow. J. Atmos. Sci., 28, 162-169.

Lindzen, R. S., 1967: Planetary waves on betaplanes. Mon. Wea. Rev., 95, 441-451.

1971: Equatorial planetary waves in shear: Part I. J. Atmos. Sci., 28, 609-622.

1972: Equatorial planetary waves in shear:

Part II. J. Atmos. Sci., 29, 1452-1463.

, and T. Matsuno, 1968: On the nature of large-scale wave disturbances in the equatorial lower stratosphere. J. Meteor. Soc. Japan, 46, 215-221.

-, and C.-Y. Tsay, 1975: Wave structure of the tropical stratosphere over the Marshall Islands area during 1 April-1 July 1958. J. Atmos. Sci., 32, 2008-2021.

Maruyama, T., 1967: Large-scale disturbances in the equatorial lower stratosphere. J. Meteor. Soc. Japan, 45, 391-408.

1968: Time sequence of power spectra of disturbances in the equatorial lower stratosphere in relation to the quasi-biennial oscillation. $J$. Meteor. Soc. Japan, 46, 327-342.

Matsuno, T., 1966: Quasi-geostrophic motions in the equatorial area. J. Meteor. Soc. Japan, 44, 2543.

Nitta, Ts., 1972: Structure of wave disturbances over the Marshall Islands during the years of 1956 and 1958. J. Meteor. Soc. Japan, 50, 85-103.

Rosenthal, S. L., 1965: Some preliminary theoretical considerations of tropospheric wave motions in equatorial latitudes. Mon. Wea. Rev., 93, 605612.

Wallace, J. M., 1973: General circulation of tropical lower stratosphere. Rev. Geophys. Space Phys., 11, 191-222.

evidence of Kelvin waves in the tropical stratosphere. J. Atmos. Sci., 25, 900-907.

Yanai, M., 1963: A preliminary survey of largescale disturbances over the tropical Pacific region. Geofis. Intern., 3, 73-84.

- and T. Maruyama, 1966: Stratospheric wave disturbances propagating over the equatorial Pacific. J. Meteor. Soc. Japan, 44, 291-294.

- - Ts. Nitta and Y. Hayashi, 1968: Power spectra of large-scale disturbances over the tropical Pacific. J. Meteor. Soc. Japan, 46, 308-323.

— torial waves penetrating from the upper troposphere into the lower stratosphere. J. Meteor. Soc. Japan, 4\%, 167-182.

— of symmetric and antisymmetric equatorial waves. J. Meteor. Soc. Japan, 48, 331-347. 


\title{
熱帯太平洋における成層圈波動擾乱の一解析
}

\author{
尾 堂 克 明* \\ 京都大学理学部地球物理学教室
}

1968 年 12 月一1969 年 4 月の熱帯西太平洋に抢ける約 10 日周期の成層圈波動擾乱について解析を行なった。この 周期帯には反対方向へ伝播する 2 種類の擾乱が見られる。ひとつは Kelvin 波で $40 \mathrm{mb}$ より下層で卓越する。もう ひとつは $40 \mathrm{mb}$ より上層で検出され, 風速の東西叔よび南北成分の变動を伴なら西進波であり, $\mathrm{n}=1$ Rossby 波と 見なされる。この 2 種類の䍐乱の鉛直構造を Lindzen $(1971 ， 1972)$ の理論に基づく計算結果と比較した。

従来の研究から，Kelvin 波が見られる時期に西風シャ層の上層と下層とに扔いて擾乱の構造が異なることが知ら れていたが，今回の解析は，この構造の相異は Rossby 波と Kelvin 波とが混在しているためであることを示唆す る。 